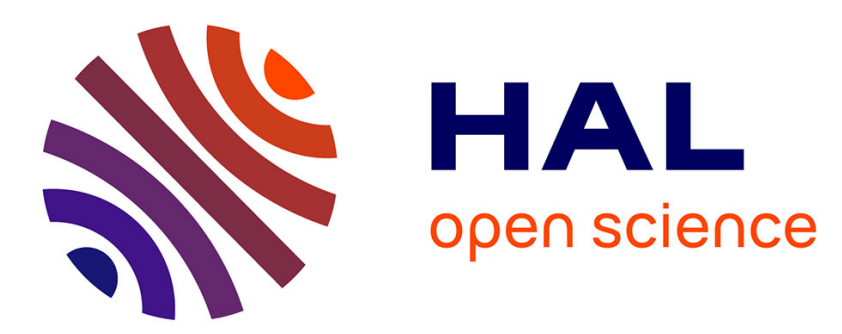

\title{
Variations in Ionic Ratios between Reference Sea Water and Marine Aerosols
}

Roger Chesselet, Jacques Morelli, Patrick Buat-Menard, Jacques •/• Orelli

\section{To cite this version:}

Roger Chesselet, Jacques Morelli, Patrick Buat-Menard, Jacques $\bullet / \bullet$ Orelli. Variations in Ionic Ratios between Reference Sea Water and Marine Aerosols. Journal of Geophysical Research, 1972, 77 (27), pp.5116-5131. 10.1029/JC077i027p05116 . hal-03403672

\section{HAL Id: hal-03403672 \\ https://hal.science/hal-03403672}

Submitted on 26 Oct 2021

HAL is a multi-disciplinary open access archive for the deposit and dissemination of scientific research documents, whether they are published or not. The documents may come from teaching and research institutions in France or abroad, or from public or private research centers.
L'archive ouverte pluridisciplinaire HAL, est destinée au dépôt et à la diffusion de documents scientifiques de niveau recherche, publiés ou non, émanant des établissements d'enseignement et de recherche français ou étrangers, des laboratoires publics ou privés. 


\title{
Variations in Ionic Ratios between Reference Sea Water and Marine Aerosols
}

\author{
Roger Chesselet, Jacques Mormlit, and Patrick Buat-Menard \\ Centre des Faibles Radioactivités, CNRS, 91 Gif-sur-Yvette, France
}

\begin{abstract}
Atmospheric particles were collected over the open sea (western Mediterranean, North Atlantic, and Norwegian Sea) by air filtration and cascade impactor sampling. The rbserved $\mathrm{K} / \mathrm{Na}$ concentration ratios exhibited marked variation and were greater than the reference ratio in bulk sea water. These concentration ratios can be related to the existence of a chemical fractionation affecting the marine aerosols produced by bubbles bursting at the sea surface. Minute amounts of terrigenous dust are found in northern hemisphere marine air in the same range of concentrations as sea-salt particles and contain sodium and potassium of primary continental origin. The presence of this terrigenous dust in the samples raises questions as to the validity of the fractionation hypothesis. In strong support of this fractionation concept are data from our laboratory based on (a) laboratory and in situ experiments with artifieially produced aerosols; $(b)$ high-volume air sampling over the Antarctic Ocean with controlled low loads of hydro-insoluble dust; and (c) coastal region sampling where silicon, aluminum, iron, and potassium provide a corrective index for potassium-rich terrigenous dust concentrations. The $\mathrm{Cl} / \mathrm{Na}$ ratios measured resemble the sea-water values, which could indicate that an enrichment of potassium takes place rather than a depletion of sodium. The $\mathrm{Ca} / \mathrm{Na}$ ratios often follow the $\mathrm{K} / \mathrm{Na}$ ratios and suggest identical enrichment of calcium. The enrichments seem to preferentially affect particles of small size $(\leq 1-2 \mu \mathrm{m})$, and long-range transport of fractionated marine aerosols can be hypothesized. This is supported by $\mathrm{K} / \mathrm{Na}, \mathrm{Ca} / \mathrm{Na}$, and $\mathrm{Mg} / \mathrm{Na}$ ratios as measured in another laboratory. These ratios, observed in ice from the central part of the East Antarctic Plateau and corrected for a terrigenous influence with the iron index, suggest a geochemical fractionation at the marine source. These data further suggest that fractionated marine aerosols can be transported far from their place of origin.
\end{abstract}

Attention has been focused on the production of sea-borne salt particles, their inorganic ion chemistry, and their distribution within the framework of an extensive study of the transport and exchange of particulate matter between oceans and continents via the atmosphere.

The data collected and the various geochemical aspects of the processes involved have been published recently [Chesselet et al., 1971]. It was concluded that chemical fractionation processes governing the sodium, potassium, and calcium ratios take place during the formation of marine aerosols. This theory, based on laboratory experiments and oceanic air investigations, constitutes the subject of our present discussion. In this study, the ionic ratios in aerosols will be compared with the following reference seawater ratios:

Copyright () 1972 by the American Geophysical Union.

$\begin{array}{ll}\mathrm{Cl} / \mathrm{Na} & 1.8 \\ \mathrm{~K} / \mathrm{Na} & 0.037 \\ \mathrm{Ca} / \mathrm{Na} & 0.036 \\ \mathrm{Mg} / \mathrm{Na} & \mathbf{0 . 0 1 1 9}\end{array}$

\section{Sample Collection and Analytical Procedures}

Sampling operations were carried out at sea, under various weather conditions, aboard oceanographic research vessels in the North Atlantic, equatorial Atlantic, Norwegian Sea, and Antarctic Ocean, and on a floating laboratory platform in the western Mediterranean. Some shipboard sampling was undertaken in collaboration with aircraft sampling. Aerosols were filtered on Delbag Microsorban absorption filters and on Millipore membranes $(0.45-\mu \mathrm{m}$ porosity) with controlled $\geq 95 \%$ collection efficiency for particles $\geq 0.1 \mu \mathrm{m}$. Filters consisting of 20 sheets of surgical gauze and a high-volume air turbine 
$\left(5000 \mathrm{~m}^{3} / \mathrm{hr}\right)$ were used over the Antarctic Ocean. In this case, the collection efficiency of $20-50 \%$ for the total mass of atmospheric aerosols was computed by utilizing the natural and artificial radioactivity of atmospheric particles. Specific air activities were compared by parallel filtrations for samples obtained on gauzes, on absorption filters, and on blue PoelmanSchneider filters (Atomic Energy standard filters). Norwegian Sea and equatorial Atlantic samples were recently obtained with a six-stage cascade impactor (Scientific Advances Co.). Investigations for samples collected on a highresolution cascade impactor require great care, because the low flow rate of air $(12 \mathrm{l} / \mathrm{min}) \mathrm{re}-$ sults in very small quantities of material deposited on impactor slides. Filters and slides were dried by infrared heat or kept frozen. The volumes of air sampled were continuously recorded by a gas-volume counter. The filters, folded in half with the collection surfaces facing each other, were sealed in double polyethylene bags to guard against contamination before and after sampling. Two high-sensitivity analytical methods were used:

1. Instrumental neutron activation (NA) analysis was performed on portions of the $a b-$ sorption filter (usually $1 / 4$ ) without any pre- or post-irradiation chemistry for chlorine, sodium, and potassium; the irradiation was followed either by $\gamma$-ray spectrometry associated with $\beta$ spectrometry for potassium determinations in the presence of sodium [Winchester, 1961; Das et al., 1969] or by high-resolution (GeLi) $\gamma$-ray spectrometry. Samples and filter blanks from the same batch and ionic metal standards and flux monitors were irradiated together in a $5 \times 10^{19}$ $\mathrm{n} \mathrm{cm}^{-2} \mathrm{sec}^{-1}$ thermal neutron flux.

2. Atomic absorption (AA) spectrometry with a Perkin-Elmer 303 instrument was used for sodium, potassium, calcium, and magnesium.

For AA spectrometry, portions of membrane filters, gauzes, and impactor slides were thoroughly washed by repeated immersions and stirring in controlled volumes of quartz twicedistilled water and finally in twice-distilled water to which small amounts of organic detergents were added. Relative recovery yields for the washing processes were checked by measuring the recovered concentration after each stage of the washing procedure. To mini- mize contamination and loss, all operations were performed in air-filtered laminar flow benches in Teflon vessels. Current precautions against interferences in atomic absorption procedures were taken. Blanks were obtained by washing unused membranes, gauzes, and impactor slides under the conditions outlined above. Some of the more recent atomic absorption analyses were performed with a graphite furnace, PerkinElmer HGA 70, at the Laboratoire de Geochimie Nucleaire, Universite de Bruxelles, Belgium.

The validity of the measurements was tested by duplicate analyses of the same portion of filter by both NA and AA procedures.

Results were found to be in close agreement $( \pm 15 \%)$ [Morelli, 1968]. Using a criterion of 2 standard deviations, the over-all precisions are chlorine, $5 \%$; sodium, 5-10\%; low concentrations of potassium, $20-30 \%$. Corrections for blanks were obtained by using identical filters, processed and handled exactly as the sampling filters but without any air passage (see Table 1 for blank Delbag filter corrections). The actual air filters were corrected for the blank for each set of analyses.

\section{Laboratory aNd IN SITU EXPERIMENTS}

Although it is difficult to ascertain whether laboratory experiments successfully simulate the processes occurring in nature, laboratory experiments with artificially produced aerosols were conducted. According to many workers [Horne, 1969 ; MacIntyre, 1970], bursting bubbles represent the main mechanism for injecting marine aerosols into the air. Various bubbling experi-

TABLE 1. Delbag Filter Blank Determinations

\begin{tabular}{ccc}
\hline & \multicolumn{2}{c}{ Concentration, $\mu \mathrm{g} / \mathrm{g}$} \\
\cline { 2 - 3 } Impurity & Pellicle & Filter \\
\hline $\mathrm{Cl}$ & $270 \pm 80$ & $1400 \pm 500$ \\
$\mathrm{Na}$ & $200 \pm 100$ & $6 \pm 3$ \\
$\mathrm{~K}$ & $\mathbf{7 0} \pm 30$ & $2 \pm 1$ \\
\hline
\end{tabular}

About 1/4 of the filter was used for each analysis; i.e., $\sim 0.15$ gram pellicle, $\sim 0.5$ gram filter. Ten blanks of each were analyzed. The plus and minus values show observed maximum fluctuations in filter blanks originated from same batches. The pellicle, which protects the filter against mechanical erosion by the wind, collects large size fraction (LSF). The filter collects small size fraction (SSF). 
ments in the laboratory may produce salt aerosols, and it is possible to observe the variations expected in ionic ratios between the initial solution (sea water) and the phase recovered (Table 2).

Experiments A1, A2, B1, B2, and C duplicate, in many respects, the experiments performed by Bloch et al. [1966] and Bloch and Luecke [1968]. Our results support their conclusions about the influence of bubbling processes upon the $\mathrm{K} / \mathrm{Na}$ ratios in marine aerosols. Experiments A1 and A2 show that crystallization is not involved when a shift in the $\mathrm{K} / \mathrm{Na}$ ratios is observed, because there is no break in the liquid phase during these experiments. We have also used these experiments to confirm gaseous chlorine formation in oceanic air [Buat-Ménard, 1970; Buat-Ménard and Chesselet, 1971]. It was shown that the $\mathrm{Cl} / \mathrm{Na}$ ratios in $\mathrm{A} 1$ and $\mathrm{A} 2$ may be quantitatively explained by a gaseous chlorine phase trapped in the distillate. This does not appear when salt particles are collected on filters. For experiments B1, B2, and C, the gaseous chlorine, which represented only a small release from particulate chlorine $(\sim 3 \%)$, was not collected on filters.

Experiments D1, D2, D3, and D4 were specifically designed to simulate more realistically the conditions under which marine aerosols are formed in nature. As in experiments B1, $\mathrm{B} 2$, and $\mathrm{C}$, no marked change in the $\mathrm{Cl} / \mathrm{Na}$ ratios were observed. The $\mathrm{Cl} / \mathrm{Na}$ ratios were always close to the sea-water value, but displacements in the $\mathrm{K} / \mathrm{Na}$ ratios were constant, showing that ionic chemical fractionation was taking place. The similarity between $\mathrm{Cl} / \mathrm{Na}$ ratios in particles and the sea-water valuc would indicate the possibility that increases in $\mathrm{K} / \mathrm{Na}$ weight ratios were due to enrichments in potassium rather than depletions in sodium. Indeed, it seems unlikely that the chlorine ions would be depleted at exactly the same rate as sodium ions during the fractionation processes.

We shall not attempt to discuss the processes of chemical fractionation-enrichment as illustrated by these experiments, since this is being done elsewhere (Morelli and Chesselet, unpublished data, 1970). Indeed, the intricacy of the great number of variables in those experiments definitely requires a very detailed discussion of the data. However, we should like to point out the particular importance of series D1 to D4
(Table 2). In this series, there is a trend to higher $\mathrm{K} / \mathrm{Na}$ values with increasing depth, where the bubbles are produced by the immersed fritted glass device.

We still are doing laboratory experiments, but we don't know yet whether this relationship is controlled either $(a)$ by the longer lifetime of the bubbles in the water before bursting or (b) by the change of the bursting bubble sizes, depending on the fact that when you produce bubbles deeper in the water the hydrostatic pressure makes them smaller. The same air flow is then carried to the surface by larger numbers of smaller bubbles. In the latter case, the data could be a clue for an enrichment dependence with the size of the bursting bubbles. We think that hypothesis $b$ is more relevant than $a$, but one must be aware that, in the two cases, a longer lifetime and more bubble surface are introduced in the system. This could indeed enhance the rate of an enrichment occurring at the surface of the bubbles in the water, before they burst. We cannot yet solve the two hypotheses.

In experiment $\mathrm{D} 4$, the added oleic acid film delays the bursting of many small bubbles at the surface, and we observed an enrichment in potassium in comparison with experiment D1 (same depth of the fritted glass device). In fact, probably two primordial effects are superposed in this experiment: one controlling the bubble sizes, the other one scavenging the potassium out of the sea water. This experiment is the most important of the series. Indeed, there is more and more evidence that the enrichment of potassium, if it does exist in nature, would be controlled to a large cxtent by the presence of organic surfactants at the surface of the sea.

Generally speaking, it can be concluded here that the data from in situ experiments support the fractionation hypothesis. $\mathrm{K} / \mathrm{Na}$ ratios in marine aerosols injected by bubbles bursting at the sea-air interface may be influenced by the same mechanisms occurring in the laboratory experiments.

\section{Northern Hemisphere Marine Air Samples}

Most of the geochemical importance of fractionated marine aerosols depends upon their capacity to be transported far from their place of origin and to be mixed within the whole troposphere. Junge [1963] has demonstrated 
Ionic Fractionation in Marine Aerosols

5119

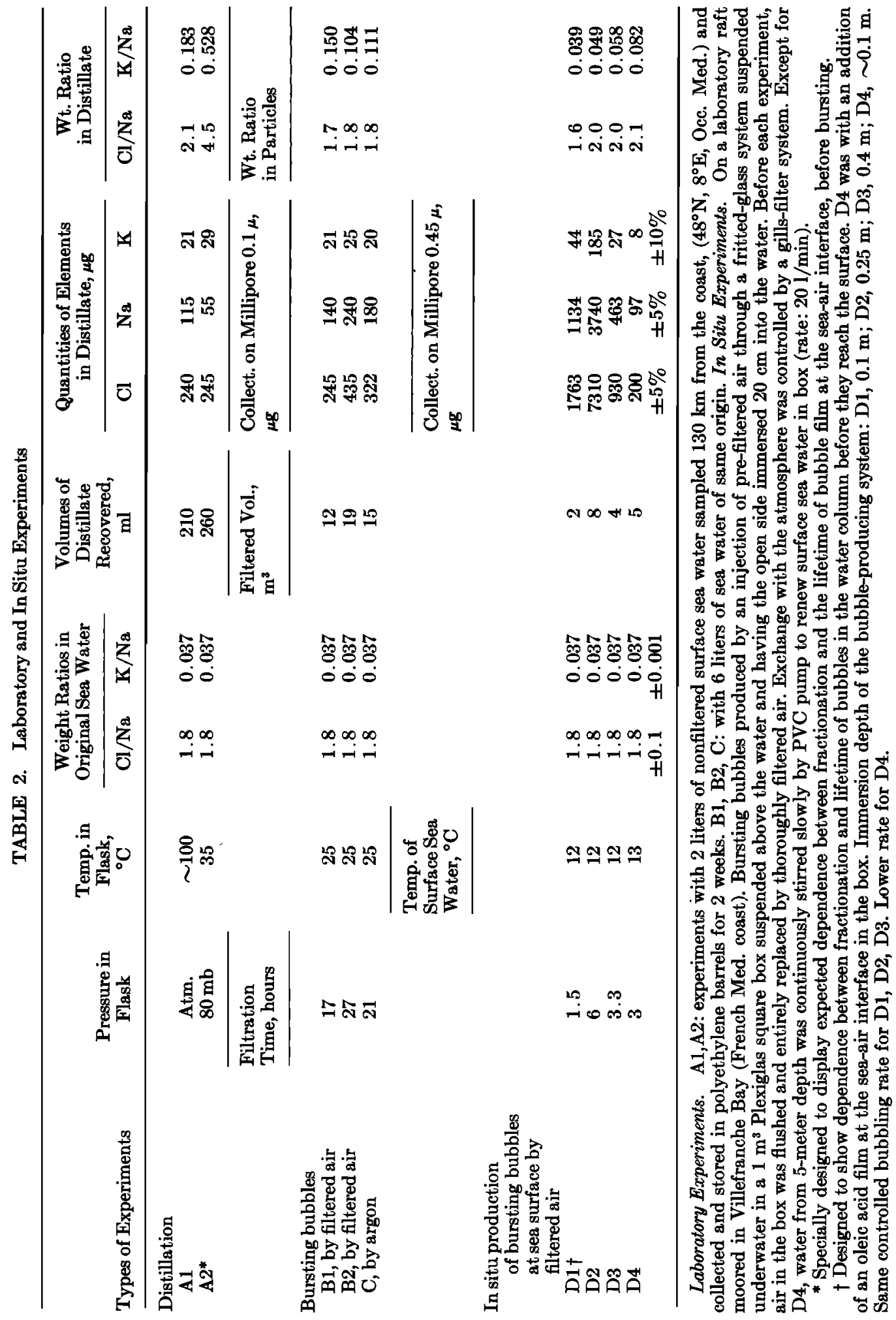


that tropospheric distributions are observed for the aerosols when they have a size range of 1-2 $\mu \mathrm{m}$ radius or smaller. On the other hand, Komabayasi [1964] has shown in laboratory experiments that a preferential fractionation may exist for small size particles of $0.4-\mu \mathrm{m}$ radius for magnesium, calcium, and strontium.

The possibility of troposphere-wide distributions was investigated by studying the occurrence of a relationship between the sizes of the particles and fractionation in samples collected at various open sea locations. We used a characteristic of the Delbag filter in many samplings to discriminate in a very crude way between the ionic ratios existing in the large size fraction from those in the small size fraction. The majority of the large size fraction was supposedly retained on the thin pellicle $(100-200$ $\mu \mathrm{m}$ porosity) placed in front of the filter to protect the filter against mechanical erosion by wind. The small size fraction was collected, with high efficiency, on the absorption filter itself.

Table 3 shows the data obtained for the absorption filter and the pellicle. These specific examples were selected because they were recently re-examined by interlaboratory comparisons to test the accuracy of previous measurements.

When one considers variations of the ionic ratios that are presumably dependent upon the presence of various populations of particles in the air, a problem arises with droplets of sea water collected on the filters. These sea-water droplets are blown into the air by waves breaking on the hull of the ship. Their quantity increases markedly with high-velocity winds and a fastmoving ship. This artificially produced sea spray can almost completely mask the ionic ratios in naturally occurring aerosol populations. This problem was taken into account in our sampling procedure.

The $\mathrm{K} / \mathrm{Na}$ weight ratios in the first part of Table 3 for the thin pellicle and absorption filter were observed in the Norwegian Sea, mainly during the periods when the ship was drifting slowly. Under slow drift, a large bubbling zone with no breaking waves exists upwind of the ship. This fact is believed to have influenced the $\mathrm{K} / \mathrm{Na}$ ratios we observed. These ratios were different from the sea-water value, for both pellicles and filters.

In order to explain these data, one can call upon the anomalous effect of 'slicks' of organics, leaking from the ship, which could scavenge potassium from sea water in quantities greater than natural sea-water organics would do. It is true that such a film must be present at the sea surface, upwind from the ship, when she slowly drifts. Then we should be close to the conditions occurring in experiment D4 (Table 1) when an added film of oleic acid enhanced the potassium enrichment. This could be a valuable bit of information, but, we have to agree that in this case the natural conditions have been biased.

Chances for shipboard contamination when the ship was stopped are very low, because the stationary samples were taken only when the wind speed was above 10 knots. The samplings were always made upwind from the rest of the ship.

In regard to all these contamination problems, we put much importance on samples taken with aircraft flying at 200 meters above the ship, with no sources of local contamination. They support our shipboard data, as is shown in Table 3 (shipboard contamination is discussed later and in the Appendix).

A floating buoy laboratory platform (FBL), the Cousteau Bouée-Laboratoire, permitted sampling in air at various heights and, occasionally, very close to the sea surface, in an undisturbed marine environment (western Mediterranean, $130 \mathrm{~km}$ from the coast of France). Despite the small amount of material recovered on the filters, fractionated $\mathrm{K} / \mathrm{Na}$ ratios occurred (see Table 3 ). In every case, the small size fraction collected on the filter itself has $\mathrm{K} / \mathrm{Na}$ ratios very far from the sea-water value. This was observed even for samples taken very close to the sea surface (11B and 12B), but, for the large size fraction collected on the pellicle, three of the samples do not show much enrichment when the uncertainty of the $\mathrm{K} / \mathrm{Na}$ ratio is considered.

When we have averaged all our data for a 3-week continuous sampling at FBL, they show the existence of a definite shift in bulk $\mathrm{K} / \mathrm{Na}$ ratios to higher values as sampling levels rise [Morelli et al., 1971].

An identical trend was observed over the Norwegian Sea when aircraft samples taken at 300-meter altitude were compared with coordinated ship samplings (Table 3 ). 
Ionic Fractionation in Marine Aerosols

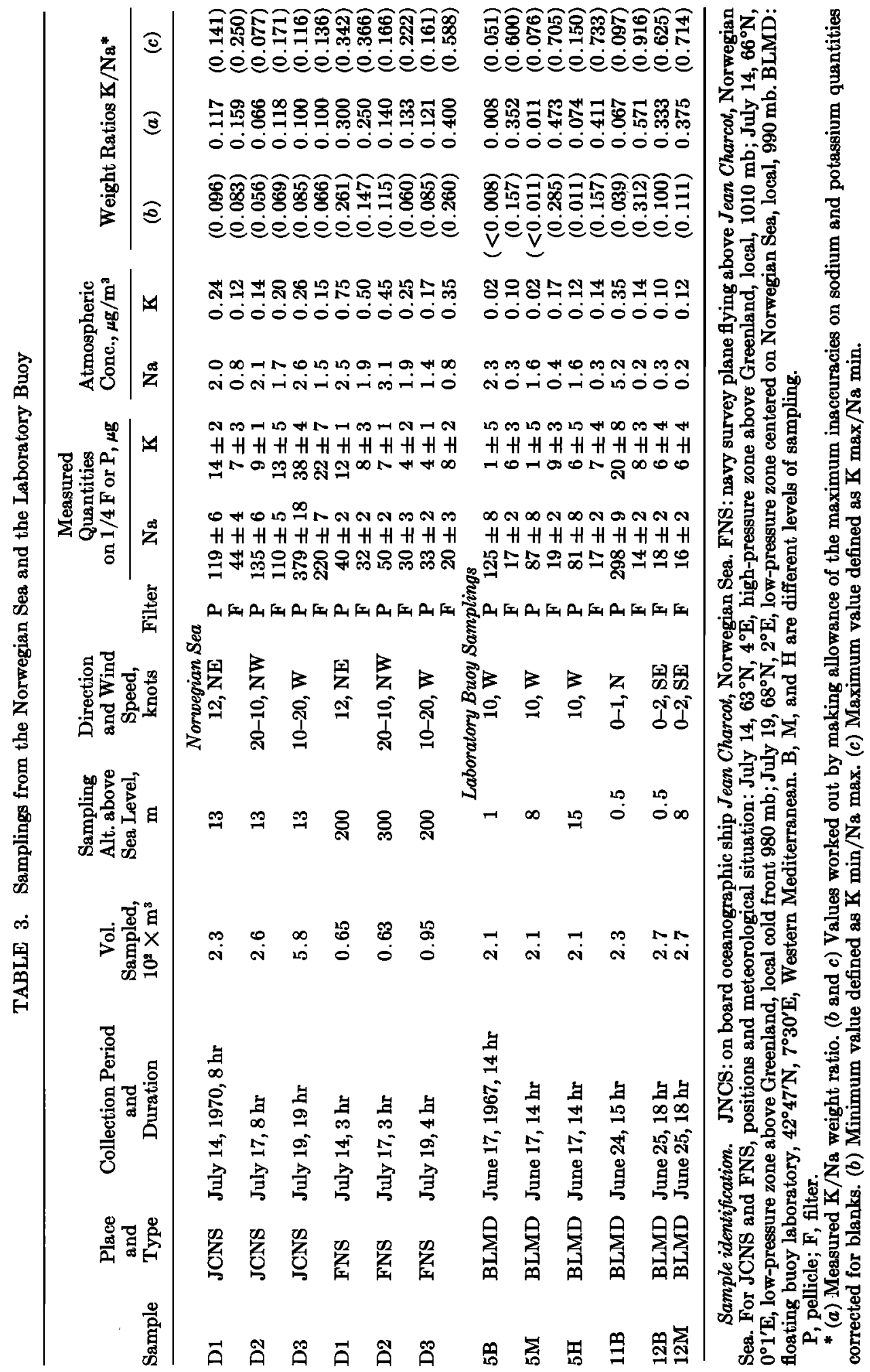


One can conclude from these data that the surface of the sea acts as the source of various types of salt particles (sea spray and aerosols produced by bubble bursting) that have different $\mathrm{K} / \mathrm{Na}$ ratios. The variations in this ratio for the filter and the thin pellicle, associated with a shift when sampling altitudes increase, can be related to the influence of the particle settling processes. Small particles more easily escape the washing mechanisms in the first layer of the marine atmosphere. This has been extensively demonstrated by Toba [1965] and Monahan [1968] for giant salt nuclei. Thus the small size fraction of the particles may penetrate further and remain longer in the marine atmosphere than the larger size fraction. The increasing proportion of this population is indicated by the shifts in the ionic ratios observed when the samples are collected further away from the source or when the local production is falling with a decreasing wind.

The existence of a fractionation versus size relationship was defined more precisely by the use of a 6-stage cascade impactor. The first run with the instrument was performed in the Norwegian Sea and was associated with filtration. We were able to extend our analysis by the AA method to the calcium content on impactor slides (Figure 1). The observed U-shaped enrichment curves look very similar to enrichment curves for iodine and bromine [Duce et al., 1967]. The NSCI2 sample was probably contaminated to some extent by droplets of sea water because of heavy winds and a moving ship.

A trend for enrichments in the small size fraction is observed for both potassium and calcium, which are quasi-identical. This substantiates the data of Komabayasi's [1964] laboratory experiments and our Delbag filter data. However, conclusions based on chemical composition versus size, as demonstrated by impactor sampling, must be carefully considered, because chemical fractionation could take place within the instrument itself (D. J. Bressan, personal communication, 1972). Indeed, the kinetics of the capture of salt particles, in moist air, by high-velocity impacts on slides could induce various phase separations followed by different types of recrystallization. The existence of such processes would evenly over-fractionate the ionic weight ratios in some stages of the impactor.

An alternative explanation can be proposed for enrichments in potassium and calcium in marine aerosols, and this has an essential bearing on the fractionation-enrichment theory. Small dust particles, originating from weathered continental soils, are blown into the air by the action of the wind. These particles have a residence time in the atmosphere sufficient to allow them to be transported over the open ocean [Junge, 1968]. Their incorporation in the samples could explain the observed ratios when non-sea-water values are found. This point must be carefully considered. Discrepancies between the measured continental dust concentrations over the oceans exist. These concentrations vary with time and place of collection. However, in the northern hemisphere the range of their concentrations is of the same order of magnitude as the concentrations of the salt particles, i.e. 0.05-5 $\mu \mathrm{g} / \mathrm{m}^{3}$ [Delany et al., 1967; Huang Chi Trach, 1969; Ferguson et al., 1970; Folger, 1970; Gillette and Blifford, 1971; also D. J. Bressan et al., unpublished data]. It has been observed that the potassium and calcium concentrations in the hydro-insoluble phase of this dust are generally $1-2 \%$ for potassium and $5 \%$ for calcium, in agreement with the average values for continental rocks [Prospero and Bonatti, 1969].

Therefore the hydro-insoluble phases of the dust cannot be involved to explain totally the 'excesses' observed in the ionic ratios. However, it can be argued that the small size clay fraction of the dust could be much more enriched in potassium and calcium of continental origin in hydro-soluble form. An incorporation of such potassium and calcium of terrestrial origin could indeed lead to the observed non-sea-water ratios.

It is clear at this point, because laboratory experiments could be biased by physico-chemical artifacts, that unequivocal arguments must be stressed in order to support the validity of a fractionation theory. This was done by extensively exploring the data presented below.

\section{Antarctic Ocean Samples}

Marine aerosols in oceanic regions with low terrigenous dust concentrations were sampled over the Antarctic Ocean on board the RV Eltanin. The terrigenous dust concentrations 

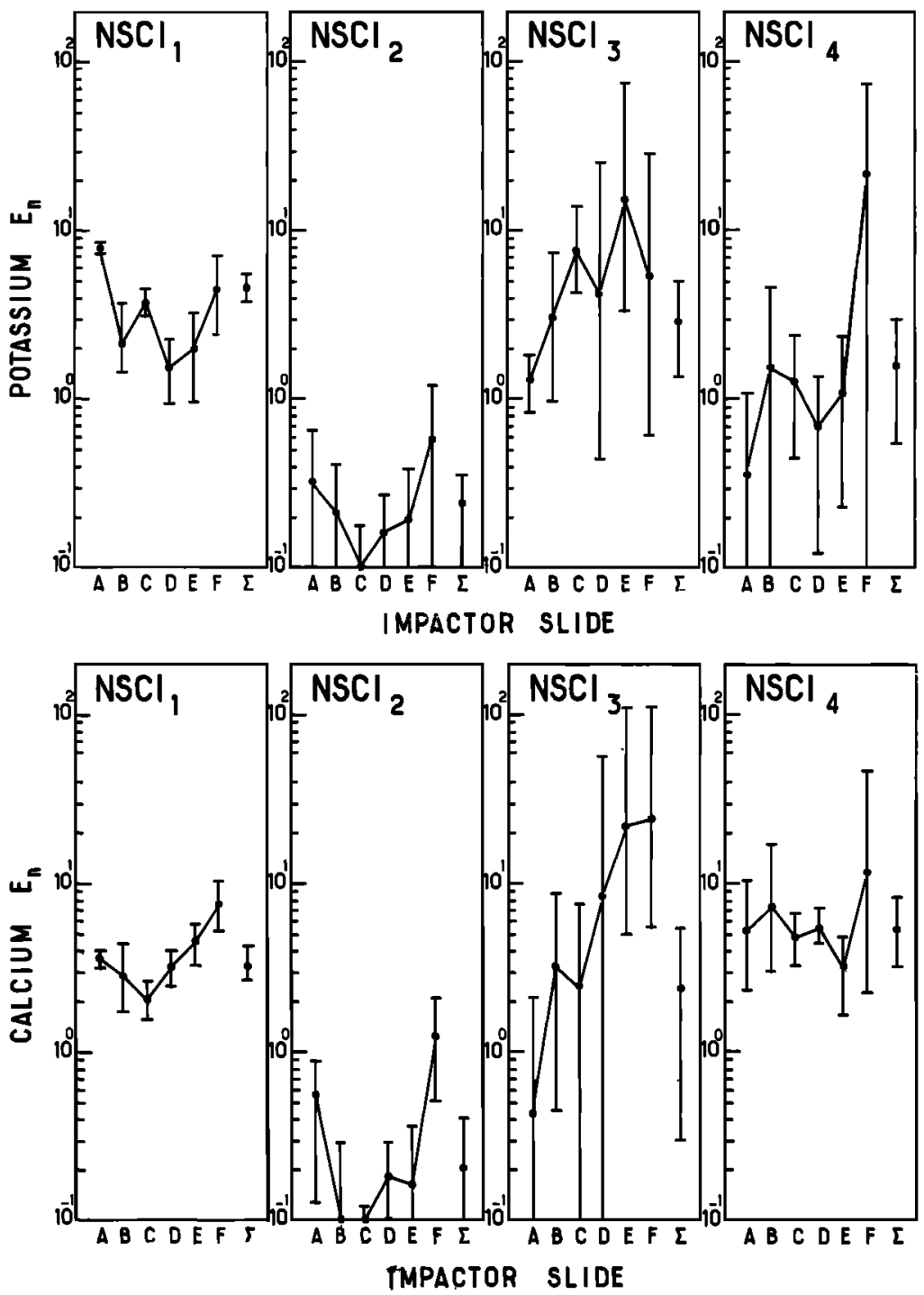

Fig. 1. Potassium and ealcium enrichments for ambient marine air particulate samples from Norwegian Sea. Six-stage cascade impactor samplings. $\mathrm{NSCI}_{1}$ : wind speed, 15-20 knots; volume sampled, $13.5 \mathrm{~m}^{3} ; 24$ hours; stationary ship $\left(63^{\circ} \mathrm{N}, 4^{\circ} \mathrm{E}\right) . \mathrm{NSCI}_{2}$ : wind speed, $>25$ knots; volume sampled, $135 \mathrm{~m}^{3} ; 18$ hours; moving ship $\left(66^{\circ} \mathrm{N}, 3^{\circ} \mathrm{E}\right)$. NSCI : wind speed, 0-5 knots; volume sampled, $90 \mathrm{~m}^{3} ; 120$ hours; moving ship $\left(73^{\circ} \mathrm{N}, 4^{\circ} \mathrm{E}\right)$. $\mathrm{NSCI}_{4}$ : wind speed, 10-15 knots; volume sampled, $73 \mathrm{~m}^{3} ; 94$ hours; moving ship $\left(70^{\circ} \mathrm{N}, 4^{\circ} \mathrm{E}\right) . E_{n}$ potassium $=$ $(\mathrm{K} / \mathrm{Na}$ aerosol $) /(\mathrm{K} / \mathrm{Na}$ sea water $)-1 . E_{n}$ calcium $=(\mathrm{Ca} / \mathrm{Na}$ aerosol $) /(\mathrm{Ca} / \mathrm{Na}$ sea water $)-$ 1. $E_{n}$ boundary values are drawn from maximum imprecisions in our measurements: $\left(E_{n}\right)_{\mathrm{m} / \mathrm{n}}$ potassium $=\left[(\mathrm{K} / \mathrm{Na})_{\operatorname{mln}}\right.$ aerosol $] /\left[(\mathrm{K} / \mathrm{Na})_{\max }\right.$ sea water $]-1 ;\left(E_{n}\right)_{\max }$ potassium $=[(\mathrm{K} /$ $\mathrm{Na})_{\max }$ aerosol $] /\left[(\mathrm{K} / \mathrm{Na})_{\operatorname{mln}}\right.$ sea water $]-1\left(E_{\mathrm{n}}\right.$ identical for calcium $)$.

were considered to be low because of the concentrations of silica in the air at these latitudes (see Table 4) (J. Servant, personal communication, 1969). Samples of large volumes of air over long time periods and large ocean areas were filtered. The high quantity of salts recovered on gauze filters permitted an accurate check of the elemental weight ratios. It should be noted that the data deal with the global population of salt particles in marine air without any kind of 
TABLE 4. Silica in Marine Air

\begin{tabular}{cc}
\hline Latitude & $\mathrm{Si}, \mu \mathrm{g} / \mathrm{m}^{3}$ \\
\hline $45^{\circ} \mathrm{N}$ & 0.110 \\
$17^{\circ} \mathrm{N}$ & 0.025 \\
$14^{\circ} \mathrm{N}$ & 0.640 \\
$8^{\circ} \mathrm{S}$ & $<0.014$ \\
$55^{\circ} \mathrm{S}$ & $<0.014$ \\
$63^{\circ} \mathrm{S}$ & 0.033
\end{tabular}

On board SS Thaladan from France to Antarctica (French polar expedition), 1967-1968. Precision (2 standard deviations), 20\%. Volume sampled, $\sim 7 \times 10^{2} \mathrm{~m}^{3}$.

separation process. For most of the cruise, the ship sailed under heavy weather conditions, and hence the relative proportion of sea spray is important. However, sea-water ratios are not observed (Table 5).

The hydro-soluble fraction of the salts was recovered by repeated thorough washings of portions of the gauze filters. This water was then filtered on preweighed Millipore membranes (0.1- and $0.45-\mu \mathrm{m}$ porosity) in order to recover non-hydro-soluble dust. For each sample, values of the dust concentration in the air are given. In fact, these levels of dust concentration must be taken as upper limits.

Instrumental neutron activation analyses recently made on those insoluble dust samples have shown the iron to be about 1\% (sodium, $1.6 \%$; potassium, $3.3 \%$ ). The value for iron indicates very little contamination by metallic particles from the ship. Such contamination sources often make the data irrelevant when one looks for trace metals in marine air, but this is not the case when the major alkaline ions are being sought; ships are not built of sodium, potassium, or calcium. However, the occurrences of shipboard contamination for fractionated salt particles is a real problem (see Appendix).

The weight ratios of $S$ (salts) and $D$ (dust) indicate clearly that the amounts of dust able to carry associated soluble potassium and calcium of continental origin are definitely too small to have any effect on the ionic ratios shown. Because the gauze filters were not highefficiency collection filters, one could infer much lower collection efficiency for the very small size dust than for the sea-salt particles. In this case, the $S / D$ ratios could have been biased.

This problem was thoroughly examined. Arti-

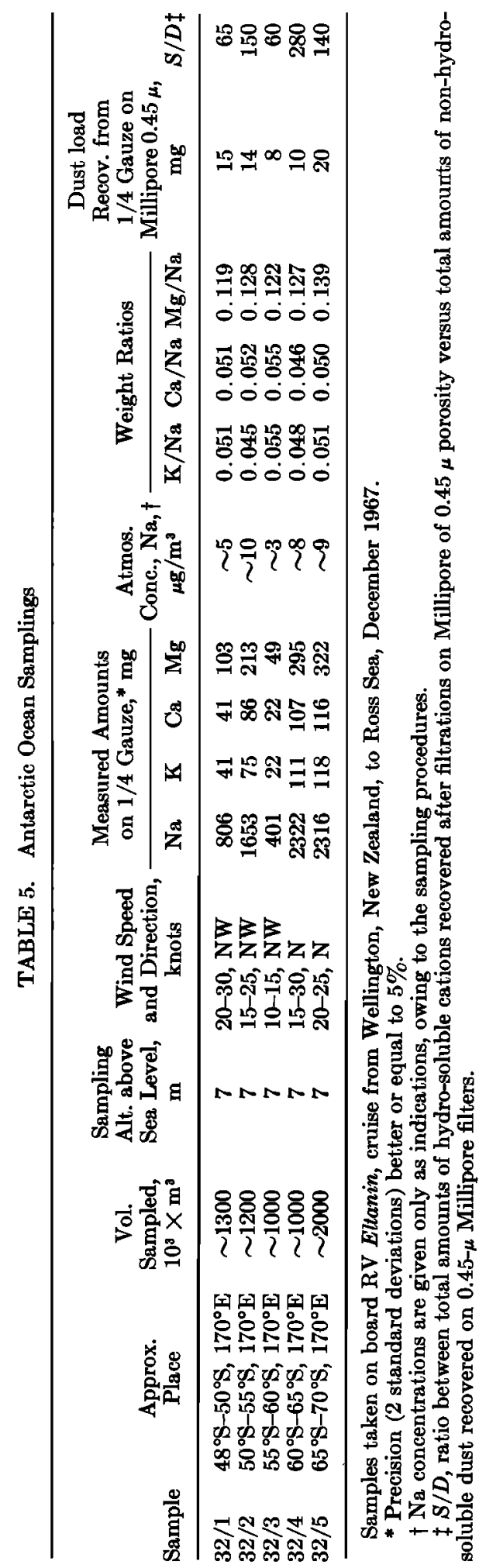


ficial and natural radioactivity of the gauze filters and of blue Poelman-Schneider filters having $99 \%$ collection efficiency and sampled with volumetric pumps were compared after parallel filtration for each sampling set. The only difference found in air-specific activities was a factor of 2 in favor of the full-efficiency filters. Thus major uncertainty in the validity of the $S / D$ ratios due to dust collection efficiency can be ruled out. Moreover, dust concentrations in the air are in good agreement with the silica concentrations shown in Table 4.

The Antarctic Ocean data support the existence of a fractionation of potassium and calcium, at least for a part of the total aerosol production. The presence of about $5-10 \%$ in weight of fractionated marine aerosols incorporated in the total population of salt particles recovered here is sufficient to explain the ratios observed. In various oceanic areas, these percentages appear to be similar. Thus one can assume that the flux of fractionated marine aerosols is very much constant for all the oceans.

\section{Coastal and Inland Samples}

When the sampling procedures do not permit accurate weighing for the atmospheric load of dust, elemental silicon, aluminum, and iron concentrations on the filters may serve to describe the presence of a terrigenous fraction. Such data also provide information on the complex mixtures occurring in the atmosphere between sea-source elements and continentalsource elements.

Another group of workers (J. Servant, Hoang Chi Trach, and E. Brichet in our laboratory, and D. Cittanova) have looked at the elemental ratios of silicon, aluminum, iron, sodium, potassium, calcium, and magnesium in air samples filtered near the ground at different types of land sites. This was done to study the chemical composition of the continental dust locally blown into the air by the wind. The analyses were performed at Service d'Etudes Analytiques, Centre d'Etudes Nucléaires, Fontenay aux Roses, France. Despite their relatively low precisions ( $\sim 20 \%$ ) when compared with the data obtained by the NA or AA method, these data are relevant to this discussion. Insight into the cations and alumino-silicate assemblages col- lected in air could ascertain whether or not fractionation in marine aerosols occurs.

From Table 6, the following points should be stressed:

First, the average crustal ratios given in Table 7 are generally not observed in the above samples. This probably reflects the existence of mixtures of sea-source elements and aluminosilicates. The $\mathrm{Al} / \mathrm{Si}$ and $\mathrm{Fe} / \mathrm{Si}$ ratios are constant in samples $1,2,3$, and 4 . In 5 and 6 , these ratios become small, probably reflecting the presence of more pure silica debris occurring in the air at this sandy coastal sampling site. In order to define average continental dust compositions, $\mathrm{Al} / \mathrm{Si}$ and $\mathrm{Fe} / \mathrm{Si}$ ratios were referred to values observed in samples 1 and 2 for inland sites, where clay minerals predominate in the soil.

Secondly, for sample 6 at the coastal sampling site in the summertime, with no wind blowing from the sea, the ratios show the presence of a mixture of the pure silica phase, the aluminosilicates, and the sea-source particles. These values do not permit precise interpretation of the chemical composition for the marine aerosol phase.

The data from 5 are important, because the wind was blowing directly from the Atlantic Ocean and much larger quantities of sodium are present with low alumino-silicate concentrations. The ratios between sodium, potassium, calcium, and magnesium are not the sea-water ratios.

An approach to establishing marine versus terrestrial compositions can be tentatively made. The ratios observed inland in 1 and 2 between cations and aluminum or iron concentrations are applied as factors to determine the sodium, potassium, calcium, and magnesium in 5 , with aluminum and iron as the alkaline terrigenous contribution, mixed with the sea-source particles. Silicon appears to be enriched too much here to be used in such computation. We then subtract these calculated concentrations from the global concentrations, in order to define the weight ratios in the marine source.

After these corrections, the 'remaining' sodium, potassium, and calcium concentrations exhibit weight ratios close to the values observed in the bulk population of marine aerosols collected on the open sea (see Table 8). In addition, the magnesium appears to be slightly 


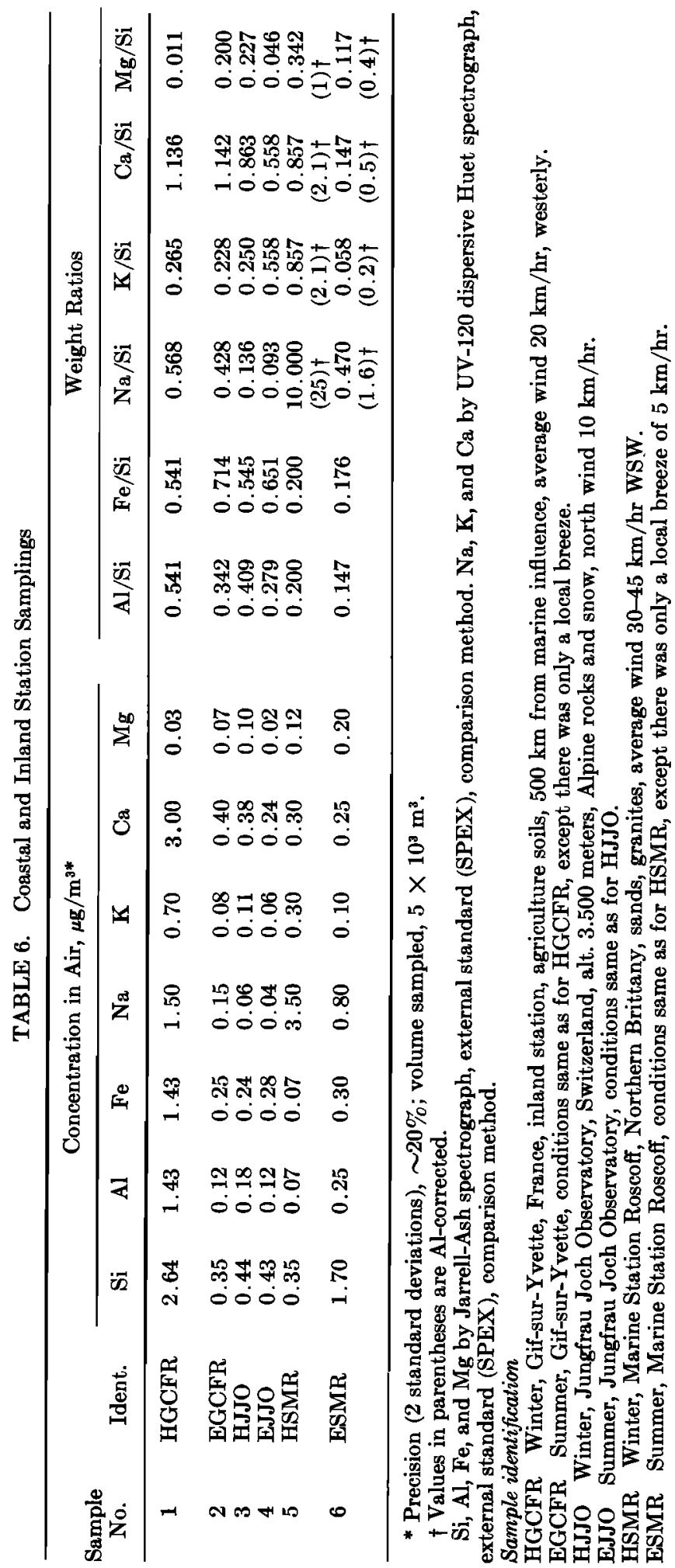


TABLE 7. Average Crustal Weight Ratios*

\begin{tabular}{ll}
\hline Ratio & Value \\
\hline $\mathrm{Al} / \mathrm{Si}$ & 0.295 \\
$\mathrm{Fe} / \mathrm{Si}$ & 0.198 \\
$\mathrm{Na} / \mathrm{Si}$ & 0.084 \\
$\mathrm{~K} / \mathrm{Si}$ & 0.074 \\
$\mathrm{Ca} / \mathrm{Si}$ & 0.147 \\
$\mathrm{Mg} / \mathrm{Si}$ & 0.083 \\
\hline
\end{tabular}

* From Taylor [1964].

depleted, which is often observed in marine aerosols [Morelli, 1968].

In samples 3 and 4 , at altitudes of 3500 meters, well above the temperature inversions, $\mathrm{K} / \mathrm{Na}$ and $\mathrm{Ca} / \mathrm{Na}$ are very high and sodium concentrations are low. This could reflect highaltitude 'background aerosol' compositions, in agreement with data from Junge [1968] and Gillette and Blifford [1971]. To ascertain the extent to which those ratios may be dependent on fractionated sea-source small particles will require more investigations.

In conclusion, the alumino-silicates versus major cations observed inland under varying conditions are not observed in air coming directly from the Atlantic Ocean. The nonterrigenous sodium, potassium, and calcium concentrations can be related to the marine source and show fractionated ratios.

\section{Antarctic Ice Data}

As was stated earlier, fractionated marine aerosols with radii less than $1 \mu \mathrm{m}$ may have their distribution controlled by long-range transport within the troposphere. Whether associated or not with precipitation, part of these particles fall on the continents, where their influence on the geochemistry of major elements can be hypothesized. However, accurate measurements of the fallout of sea-source salts over the continents are very difficult, because the marine source is often overwhelmed by local terrigenous sources or human pollution. However, the geochemistry of this fallout can be successfully studied in polar ice samples. Recent extensive research on concentrations of impurities in super-pure Antarctic ice has opened the possibility of differentiating between the contributing sources (continental, marine, and extraterrestrial) and their associated chemistry [Hanappe et al., 1968; Murozimi et al., 1969; Vosters et al., 1970].

Data in Table 9 were kindly provided by $M$. Vosters, F. Hanappe, and E. Picciotto from Service de Geochimie Nucleaire, Universite de Bruxelles, Belgique. The main purpose of their study was to estimate the influx of extraterrestrial matter (M. Vosters et al., unpublished data). We shall discuss only the data on the terrigenous and marine sources. The ice samples from the central part of the East Antarctic Plateau were collected with extreme precaution against contamination and were brought back to the laboratory in a frozen state. Because of the low concentration of elements, careful analytical procedures were utilized (AA and NA) to measure sodium, potassium, calcium, magnesium, iron, nickel, and manganese [Hanappe, 1970; Vosters, 1971].

In Table 9, the sea-water ratios for the alkaline ions are not observed. The iron concentrations were used to correct these ratios for the terrigenous influence. First, the iron concentrations were corrected for the extraterrestrial iron. This contribution represented only about $20 \%$ of the total iron. A value of $5.7 \%$ iron in the terrigenous-source crustal rocks [Taylor, 1964] was applied in order to calculate the amount of the terrigenous fraction incorporated in the samples. The rocks uncovered by ice in the Antarctic are the most likely source for large parts of the terrestrial contribution. The values for the cation percentages in the terrigenous source were also considered to be the percentages occurring in the crustal average rocks. It should be noted that the iron concentrations could have been underestimated because of incomplete dissolution by aqua-regia of acid-resistant alumino-silicates, presumably also present in the terrigenous fraction. There are strong indications that this was not the case

TABLE 8. Coastal Sampling 5 (HSMR)

\begin{tabular}{|c|c|c|c|}
\hline Element & $\begin{array}{c}\text { Terrigenous } \\
\text { Corrected } \\
\text { Conc., } \mu \mathrm{g} / \mathrm{m}^{3}\end{array}$ & Ratio & $\begin{array}{c}\text { Computed } \\
\text { Wt. Ratio in } \\
\text { Marine Source }\end{array}$ \\
\hline $\mathrm{Na}$ & 2.70 & $\mathrm{~K} / \mathrm{Na}$ & 0.100 \\
\hline $\mathbf{K}$ & 0.27 & $\mathrm{Ca} / \mathrm{Na}$ & 0.060 \\
\hline $\mathrm{Ca}$ & 0.16 & $\mathrm{Mg} / \mathrm{Na}$ & 0.033 \\
\hline $\mathbf{M g}$ & 0.09 & & \\
\hline
\end{tabular}




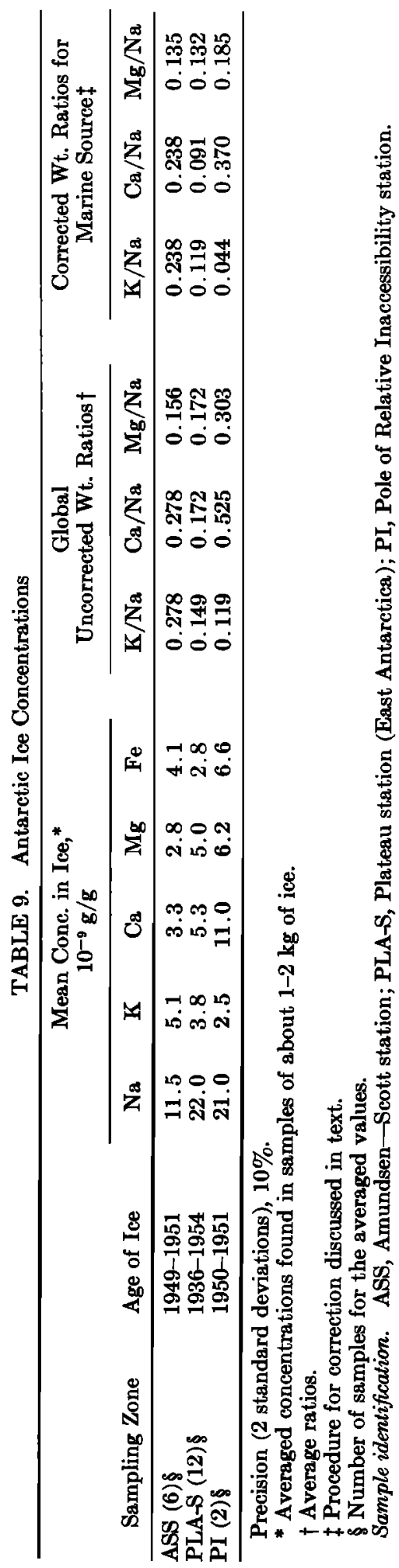

and that there were no losses in the recovery of iron during the analytical procedure. This is also confirmed by recent data of Boutron et al. [1972] and R. A. Duce (personal communication, 1972). They showed that the quantities of iron recovered in snow samples collected in a similar area in East Antarctica are not changed by an attack by HF after dissolution by aquaregia.

Table 9 also gives the values for the ratios after a terrigenous correction for each sample. The sea-water ratios are still not observed.

The ice samples integrate a longer span of time than locally filtered air. Thus, they provide good statistical values and are probably representative of a situation occurring on a large geochemical scale. The existence of chemical fractionation globally affecting the marine source on the East Antarctic Plateau is shown by the data of Vosters et al. [1970].

In this area, very low rates of snow accumulations are observed: $\sim 3 \mathrm{~g} \mathrm{~cm}^{-2} \mathrm{yr}^{-\mathbf{x}}$ [Picciotto et $a l ., 1964]$. Such low accumulation rates are currently explained by a meteorological shielding effect against direct penetration of oceanic air. In this specific zone, the marine source appears to be more fractionated than in zones such as coastal regions [Vosters, 1971; Boutron et al., 1972] and presumably West Antarctica [Murozimi et $a l ., 1969]$. These regions are more directly under the influence of intrusion of marine air, as is shown by a higher snow accumulation rate.

We feel that such a relationship between fractionation in the marine source and the 'ages' of the oceanic air could be related to a sizefractionation relationship that was used to explain variations in ratios in marine air particles. Indeed, a sorting process from large to smaller particles could control the trends observed in fractionated ratios; i.e., the fractionation is more marked when the distance and time between the sampling location and the oceanic source increase.

\section{Summary and Conclusion}

It has been tentatively demonstrated by laboratory experiments that, at the very beginning of their history in the atmosphere, part of the aerosols produced by bursting bubbles at the surface of the sea do not have the elemental $\mathrm{K} / \mathrm{Na}$ weight ratio that exists in the bulk sea water. 
This ratio shows large variations over time and space for particles sampled in open sea marine air under various conditions. This situation probably reflects the presence of a complex population of atmospheric particles, with proportions largely controlled by settling processes. These particles are: (a) sea-spray particles, presumably with the sea-water ratios; $(b)$ terrigenous dust of small size, probably enriched with cations of primary continental origin in a hydro-soluble phase; and $(c)$ ionic fractionated marine aerosols.

The existence of this last category of seasource particles is shown by data obtained where the amounts of dust of any elemental composition is much too small to have an influence when non-sea-water weight ratios are observed. This was the case for our samples from the Antarctic Ocean and for coastal samples.

When scrutinized, the open sea data seem to demonstrate that the smaller size categories of marine aerosols are probably the more fractionated. In upper layers of the marine atmosphere, their concentrations may compete with the terrigenous dust load to govern the cations ratios.

The $\mathrm{K} / \mathrm{Na}$ and $\mathrm{Ca} / \mathrm{Na}$ weight ratios appear to depend upon the same processes and same proportions of fractionated aerosols in the marine atmosphere. The $\mathrm{Cl} / \mathrm{Na}$ ratios remain close to the sea-water value. Thus, when compared with the sodium concentrations, potassium and calcium concentrations in particles appear to be essentially controlled by a process of enrichment at the sea-air interface. Many aspects of the chemistry of such an enrichment are not yet fully explained and will receive further investigation.

If part of the enriched marine aerosols have sizes small enough to be transported far from their place of origin, their influence on elemental ratios in precipitation can be traced. This was done by looking at the major element ratios in ultrapure Antarctic ice. After a correction for the influence of terrigenous impurities the remaining $\mathrm{K} / \mathrm{Na}, \mathrm{Ca} / \mathrm{Na}$, and $\mathrm{Mg} / \mathrm{Na}$ ratios are fractionated in comparison to the sea-water values.

In conclusion, bubbles bursting at. the sea surface seem to inject into the atmosphere quantities of ionic fractionated aerosols large enough to affect the geochemistry of atmospheric particles.

\section{APPENDIX}

On board a ship, there are many sources and processes that could introduce into the filtered air ions having ratios unlike those in sea water. One source of shipboard contamination could be the smoke. Despite all precautions that were taken, many of our filters have been darkened by smoke constituents. In regard to the effect of this kind of contamination for sodium, potassium, and calcium, our arguments are as follows:

a. We have never found any kind of correlation between the degree of darkness of the filters and variations in ionic ratios.

$b$. Two important parameters are the weight of ashes produced by a given volume of fuel and their average compositions in alkaline ions. The average ash concentration produced by the fuel is at maximum $0.01 \%$ [Battelle Memorial Institute, 1959]. The concentration of ashes is as follows: $\mathrm{Na}_{2} \mathrm{O}, 0.8$ to $12.5 \% ; \mathrm{K}_{2} \mathrm{O}, 0$ to $1.8 \%$; $\mathrm{CaO}, 1$ to $11 \%$ [Sürü, cited in Zul'Fugarly, 1964], and it is probably much less than these values [Bertine and Goldberg, 1971]. Using these data, we see that 1 ton of fuel will produce about 10 grams of sodium, 1 gram of potassium, and so on. The average consumption in fuel of our research vessels is about 10 tons per 24 hours. Then, 100 grams of sodium is injected for about the duration of our average sampling. The dilution coefficients that were studied for many years for radioactive smoke released from nuclear reactors at Saclay $\mathrm{Nu}$ clear Center for the same geometry between the exhauster and sampler, same wind conditions, and for about the same flow rate of exhausted vapor, are $10^{7}$ to $10^{9}$. Then one can reasonably predict that, for 24 hours of sampling, the average amount of sodium that could have the smoke as its origin is about 10 to $1 \mu \mathrm{g}$ on our filters. Quantities of ashes 10 times higher may darken the filters, but the associated sodium and potassium quantities cannot influence the weight ratios we observed, which are based on 100 to $1000 \mu \mathrm{g}$ of sodium per filter.

c. An additional source of contamination by the exhauster could be small quantities of sea water vaporized in the exhauster. From technical discussions with engineers and measurements we made on board research vessels, an escape of less than 1 liter of sea water per hour can be assumed. Taking the same dilution parameter, 
this again gives an amount of salt far less than the amount of salt collected on filters.

Another source of shipboard contamination could be worse: drying of sea-water droplets on the surface structure of the ship could introduce, during crystallization, a chemical fractionation between the cations. Blown again in the air after drying, these secondary fractionated seasalt particles could in fact contaminate the samples. However, we do not know yet whether these processes really occur and how to measure this effect. The only argument we have on this aspect of the question is that, whenever our samples have been taken, the rate of rainfall was extremely high, repeatedly washing the superstructure of the ship, and that all samples were collected upwind from the ship. Again, the arguments for the existence of a true fractionation derived from low-altitude aircraft samplings are of extreme importance in this discussion.

Acknowledgments. We wish to thank for their helpful cooperation in the framework of this study Dr. J. Servant, Dr. Hoang Chi Trach, and coworkers; Pr. E. Picciotto and members of Service, de Géochimie Nucléaire, Université de Bruxelles; Dr. M. Vosters and Dr. F. Hanappe. We thank the scientific staff and crew members of RV Eltanin, Jean Charcot, Cousteau Bouée-Laboratoire, the Service Hydrographique de la Marine Nationale, and the Aeronautique Navale Française for their very kind support. We are especially indebted to Dr. D. Nordemann for air sampling in the Antractic Ocean and A. Barlet for his measurements on the Antarctic samples. We are grateful to Pr. P. Albert and the staff of Laboratoire d'Analyse par Activation Pierre Sue. Helpful criticisms and suggestions by Dr. J. Labeyrie during this work are gratefully appreciated.

\section{REFERENCES}

Battelle Memorial Institute, Report of ASME Research Committee on Corrosion and Deposits from Combustion Gases, Pergamon, New York, 1959.

Bertine, K. K., and E. D. Goldberg, Fossil fuel combustion and the major sedimentary cycle, Science, 179, 233-235, 1971.

Bloch, M. R., and W. Luecke, Uneiheitliche Verschiebungen der Ionenverhaltniss Zwischen Meereswasser und Niederschlagen durch Gischtbildung, Naturwiss., 55, 1-3, 1968.

Bloch, M. R., D. Kaplan, V. Kertes, and J. Schnerb, Ion separation in bursting air bubbles:
An explanation for the irregular ion ratios in atmospheric precipitations, Nature, 209, 802$803,1966$.

Boutron, C., M. Echevin, and C. Lorius, Chemistry of polar snows, estimation of rates of deposition in Antarctica, Geochim. Cosmochim. Acta, in press, 1972.

Buat-Ménard, P., Contribution à l'étude du cycle géochimique du chlore d'origine marine, thèse de doctorat de 3ème cycle, Faculté des Sciences de Paris, 1970.

Buat-Ménard, P., and R. Chesselet, Sur la présence de chlore 'gazeux' d'origine marine dans l'atmosphère, Compt. Rend., $272,1330-1332,1971$.

Chesselet, R., J. Morelli, and P. Buat-Ménard, Some aspects of the geochemistry of marine aerosols, paper presented at Nobel Symp. 20, The Changing Chemistry of the Oceans, Aspenäsgärden, Sweden, August 16-20, 1971.

Das, H. A., J. G. Van Raaphorst, and H. J. L. M. Umans, in: Modern Trend in Activation Analysis, Publ. s12, vol. 1, National Bureau of Standards, Gaithersburg, Md., 1969.

Delany, A. C., Audrey Claire Delany, D. W. Parkin, J. J. Griffin, E. D. Goldberg, and B. E. F. Reimann, Airborne dust collected at Barbados, Geochim. Cosmochim. Acta, 31, 885-899, 1967.

Duce, R. A., H. H. Woodcock, and J. L. Moyers, Variation of ion ratios with size among particles in tropical oceanic air, Tellus, 19, 369-379, 1967.

Ferguson, W. S., J. J. Griffin, and E. D. Goldberg, Atmospheric dusts from the North Pacific: A short note on a long range eolian transport, J. Geophys. Res., 75, 1137-1139, 1970.

Folger, D. W., Wind transport of land-derived mineral, biogenic and industrial matter over the North Atlantic, Deep Sea Res., 17, 337-352, 1970.

Gillette, D. A., and J. H. Blifford, Jr., Composition of tropospheric aerosols as a function of altitude, J. Atmos. Sci., 28, 1199-1200, 1971.

Hanappe, $F$., Contribution à la chimie des neiges antaretiques, Estimation du taux de déposition de matière extraterrestre, thèse, Université Libre de Bruxelles, 1970.

Hanappe, F., M. Vosters, E. Picciotto, and S. Deutsch, Chimie des neiges antarctiques et taux de déposition de matière extraterrestre, deuxième article, Earth Planet. Sci. Lett., 4, 487-496, 1968.

Hoang Chi Trach, Etude de la retombée de fer 55 artificiel, Application à l'estimation de la retombée de fer naturel stratosphérique, thèse de doctorat d'état, Faculté des Sciences de Paris, 1969.

Horne, R. A., in Marine Chemistry, edited by J. P. Riley, Interscience, New York, 1969.

Junge, C. E., Chemical analysis of aerosol particles and gas traces in the island of Hawaii, Tellus, 9, 528-537, 1957.

Junge, C. E., in Air Chemistry and Radioactivity, Academic, New York, 1963. 
Junge, C. E., Airborne dust at Barbados and its relation to global tropospheric aerosols, Geo chim. Cosmochim. Acta, 32, 1219-1222, 1968.

Komabayasi, M., Primary fractionation of chemical components in the formation of submicron spray drops from sea salt solution, J. Meteorol. Soc. Jap., 4R, 309-316, 1964.

MacIntyre, F., Geochemical fractionation during mass transfer from sea to air by breaking bubbles, Tellus, 22, 451-461, 1970.

Monahan, E. C., Sea spray as a function of low elevation wind speed, J. Geophys. Res., 73, 11271137, 1968.

Morelli, J., Contribution à l'étude de la composition des aérosols formés à la surface de la mer: Leur rôle dans les échanges de matière entre l'océan, l'atmosphère et le continent, thèse de doctorat de 3ème cycle, Faculté des Sciences de Paris, 1968.

Morelli, J., P. Buat-Ménard, and R. Chesselet, Mise en évidence dans l'atmosphère marine d'aérosols enrichis en potassium et calcium ayant la surface de la mer pour origine, Compt. Rend., E7\%, 812-815, 1971.

Murozimi, M., T. J. Chow, and C. Patterson, Chemical concentrations of pollutant, lead aerosols, terrestrial dusts and sea salts in Greenland and Antarctic snow strata, Geochim. Cosmochim. Acta, 39, 1247-1294, 1969.

Parkin, D. W., D. R. Phillips, R. A. L. Sullivan, and L. Johnson, Airborme dust collections over the North Atlantic, J. Geophys. Res., 75, 1782$1793,1970$.
Picciotto, E., G. Crozaz, and W. de Breuck, Rate of accumulation of snow at the South Pole as determined by radioactive measurements, $\mathrm{Na}$ ture, 203(4943), 393-394, 1964.

Prospero, J. M., and E. Bonatti, Continental dust in the atmosphere of the eastern equatorial Pacific, J. Geophys. Res., 74, 3362-3371, 1969.

Taylor, S. R., Abundance of chemical elements in the continental crust: A new table, Geochim. Cosmochim. Acta, 28, 1273-1285, 1964.

Toba, Y., On the giant sea-salt particles in the atmosphere, 1, 2, 3, Tellus, 17, 131-145 and 365382; Tellus, 18, 132-145, 1965.

Vosters, M., Contribution à la chimie des neiges antarctiques, Composition et origine des aérosols atmosphérique, thèse, Université Libre de Bruxelles, 1971.

Vosters, M., F. Hanappe, and E. Picciotto, Contribution to the hydrochemistry of the Antarctic ice-sheet, paper presented at the International Symposium on Hydrochemistry and Biogeochemistry, Sci. Counc. of Jap., Tokyo, Japan, Sept. 6-12, 1970.

Winchester, J. W., Determination of potassium in silicate minerals and rocks by neutron activation analysis, Anal. Chem., 33, 1007, 1961.

Woodcock, A. H., Salt nuclei in marine air as a function of altitudes and wind force, J. Meteorol., 10, 363-371, 1953.

Zul'Fugarly, D. I., Verbreitung der Spürenelemente in Kaustobiolithen, Organismen, Sedimentgesteinmen un Schichtwässern, Vets. Deutscher Verlag für Grundstoffindustrie, Leipzig, 1964. 